\title{
EDITORIAL 22.3 - A Associação Brasileira de Psicologia Escolar e Educacional - ABRAPEE em defesa da democracia e da emancipação humana
}

\author{
Nós vos pedimos com insistência: \\ Nunca digam isso é natural \\ Diante dos acontecimentos de cada dia. \\ Numa época em que reina a confusão, \\ Em que corre o sangue. \\ Em que se ordena a desordem, \\ Em que o arbítrio tem força de lei, \\ Em que a humanidade desumaniza... \\ Não digam nunca: isso é natural \\ A fim de que nada passe por imutável. \\ Bertolt Brecht (1986).
}

Nos últimos dias, vivemos no país muitas discussões sobre direitos humanos, democracia, liberdade, entre outros assuntos, no mínimo, bastante polêmicas. A ABRAPEE elaborou e divulgou o Manifesto pela Democracia (Associação Brasileira de Psicologia Escolar e Educacional, 2018, p. 1), do qual extraímos alguns trechos para mostrar o posicionamento adotado pela Associação em relação à defesa dos direitos humanos, entre eles, de acesso e permanência na escola, conforme podemos ver a seguir

(...) defendemos a educação para todos e todas, a Constituição "Cidadã" Brasileira de 1988, a Lei de Diretrizes e Bases da Educação Brasileira de 1996 e toda a Legislação de Direitos Humanos e Sociais aprovada no Brasil desde o final dos anos 1980: o Estatuto da Criança e do Adolescente, o Sistema Único de Saúde, o Sistema Único de Assistência Social, a Declaração da Pessoa com Deficiência, o Estatuto da Juventude, o Estatuto do Idoso, o Plano Nacional de Educação para os Direitos Humanos, para citar algumas das principais conquistas democráticas de nosso país.

(...)

Continuaremos na defesa de nossas crianças, adolescentes, jovens, adultos, idosos, protagonistas das políticas sociais por nós construídas. Continuaremos na defesa intransigente das políticas públicas que constituímos para todos os segmentos da população para que cada vez mais, atendam às necessidades básicas de nossa sociedade, aos anseios de uma vida cada vez melhor. Continuaremos na defesa da Educação, em todos os seus níveis, como um dos maiores bens de uma sociedade e que deve ser universal, com qualidade, laica, socialmente referenciada e que permita a todos e todas o acesso amplo e irrestrito ao pensamento crítico e ao conhecimento socialmente acumulado.

Historicamente, muitas lutas foram travadas para garantir os direitos humanos e, entre eles, o acesso e permanência na escola. Boto (2005) afirma que o direito à educação se deu em três gerações. A primeira delas, na garantia de acesso à educação, que no nosso país encontrou muitos avanços e hoje temos uma grande parcela de crianças e jovens que freqüentam a escola. A segunda, remete ao fato de criar condições para que todos aprendam, o que, ainda, é bastante precário quando vemos que o fracasso escolar assola o pais; quando vemos tantas crianças sendo encaminhadas para avaliação por apresentarem problemas no processo de escolarização; quando diagnósticos são realizados de forma aligeirada culminando a solução namedicalização; na precarização da formação de professores e nas suas condições de trabalho; no incipiente investimento dado à educação, entre tantos outros fatores que dificultam a apropriação dos conhecimentos. A terceira geração, segundo o autor, "(...) pauta-se pelo signo da tolerância, mediante a qual o encontro de culturas se faça e se refaça constantemente em uma sempre renovada convivência e partilha entre diferentes nações, diferentes povos, diferentes comunidades, diferentes grupos sociais, diferentes pessoas". (p. 790).

A história mostra que os homens estão criando estratégias para usufruir do direito à educação, mas o processo é cheio de contradições, com avanços e retrocessos, como o que estamos vivendo neste período: 
aprovação da reforma do Ensino Médio que, na defesa da liberdade de escolha dos estudantes, camufla o ideário liberal que insiste em retirar possibilidades dos alunos, principalmente da classe trabalhadora, de acesso ao conhecimento socialmente acumulado pela Humanidade; busca da aprovação da Escola Sem Partido que, na defesa da família, quer impedir que professores possam ter posicionamento político no sentido de levar os alunos a conhecerem a essência dos fatos, para além da aparência, visando colocar uma mordaça nos profissionais que explicitam, por meio de conteúdos curriculares, de conhecimentos científicos, possibilidades de levar o estudante a desenvolver uma consciência crítica sobre o mundo, o país e sobre sua própria condição de humanidade; proibição da discussão de gênero, entre tantos outros impedimentos que desconsideram os direitos humanos e as inúmeras conquistas nos campos da Educação e da Psicologia.

Nunca se falou tanto em democracia, entre aqueles que se opõem à exploração dos homens pelos próprios homens, como entre aqueles que a defendem, mesmo quando as ações propostas, as falas corriqueiras, demonstram o contrário. A questão da democracia foi discutida em muitas situações pela ABRAPEE, em especial na palestra de abertura do último XIII Congresso Nacional de Psicologia Escolar e Educacional-XIII CONPE, realizado em Salvador em 2017, no qual o Professor Dermeval Saviani fez uma belíssima exposição sobre o significado do conceito de democracia e sua relação com a educação, e analisou que não basta apresentar a democracia formal; é necessário criar condições para desenvolver a democracia real, comprometida com a emancipação humana. Saviani (2027, p. 661) afirma que "(...) diante da crise estrutural da atual forma de sociedade impõe-se sua transformação radical, o que é obra da práxis revolucionária que, entretanto, não se viabilizará sem o preenchimento de condições subjetivas". Condições objetivas e subjetivas precisam ser transformadas, criadas para que a práxis revolucionária possa ter espaço em períodos de opressão.

A coletividade deve ser o mote daqueles que estão compromissados, politicamente, pela defesa dos direitos humanos, entre eles, o direito à educação de qualidade, educação emancipadora, que possibilite o processo de humanização de todos envolvidos com a educação. Nesse aspecto, esperamos que a leitura dos artigos publicados neste número da Revista contribua para a instrumentalização de estudantes, professores e demais profissionais na compreensão da relação estabelecida entre desenvolvimento humano, aprendizagem, Psicologia, Educação e condições histórico-sociais.Os temas abordados pelos autores são diversos, falando de letramento, de bullying, da formação de leitores, das queixas escolares, das cotas, da medicalização, da Psicologia Escolar e de muitos outros que foram objeto de estudo.

Finalizamos este editorial informando os leitores que no ano de 2019 nossa revista será bilíngüe, publicando todos os artigos em português e inglês e que a publicação terá fluxo contínuo. Nossa pretensão é ampliar a possibilidade de acesso às produções na área de Psicologia e áreas afins, assim como levar ao leitor, o mais rápido possível, as pesquisas realizadas em nosso campo.

Boa leitura.

\section{Referências}

Associação Brasileira de Psicologia Escolar e Educacional. Manifesto pela Democracia.Recuperado: 01 nov. 2018. Disponível: https:// www.facebook.com/pg/abrapee.psc/post

Boto, C. (2005). A educação escolar como direito humano de trêsgerações: identidades e universalismos. Educ. Soc. [online]. 26(92), 777-798. Recuperado: 01 nov. 2018. Disponível: http://www.scielo.br/pdf/es/v26n92/v26n92a04.pdf

Brecht, B. (1986). Poemas 1913-1956. 2a. ed. São Paulo: Brasiliense.

Saviani, D.(2017). Democracia, educação e emancipação humana: desafios do atual momento brasileiro. Psicologia Escolar e Educacional,21(3), 653-662.Recuperado: 01 nov. 2018. Disponível: http://www.scielo.br/pdf/pee/v21n3/2175-3539-pee-21-03-653.pdf

Silvia Maria Cintra da Silva ${ }^{1}$, https://orcid.org/0000-0003-0834-5671

Marilda Gonçalves Dias Facci², https://orcid.org/0000-0001-7443-490X

Marilene Proença Rebello de Souza ${ }^{3}$, https://orcid.org/0000-0002-8297-5674

1 Universidade Federal de Uberlândia, MG, Brasil.

2 Universidade Estadual de Maringá, Maringá, PR, Brasil.

3 Universidade de São Paulo, São Paulo, Brasil.

License information: This is an open-access article distributed under the terms of the License (type CC-BY), which permits unrestricted use, distribution and reproduction in any medium, provided the original article is properly cited. 